\title{
GEOGRAFIA DO PODER, ATORES TRANSNACIONAIS E COMUNICAÇÃO NOS PROCESSOS DE RADICALIZAÇÃO RELIGIOSA
}

\author{
- JOÃO LUÍS FERNANDES 1 \\ - MARGARIDA FRANCA ${ }^{2}$ \\ - RUI MARTINS 3
}

${ }^{1}$ CEIS20 - Centro de Estudos Interdisciplinares do Século XX / Universidade de Coimbra e CEGOT - Centro de Estudos de Geografia e Ordenamento do Território / Faculdade de Letras da Universidade de Coimbra. E-mail: jfernandes@fl.uc.pt

2 CEGOT - Centro de Estudos de Geografia e Ordenamento do Território/Faculdade de Letras da Universidade de Coimbra e CITER - Centro de Investigação de Teologia e Estudos da Religião. E-mail: margfranca@gmail.com

${ }^{3}$ CEGOT - Centro de Estudos de Geografia e Ordenamento do Território/Faculdade de Letras da Universidade de Coimbra.E-mail: ruim66@gmail.com.

Recebido em: 07/01/2019

Aprovado em: 23/08/2019

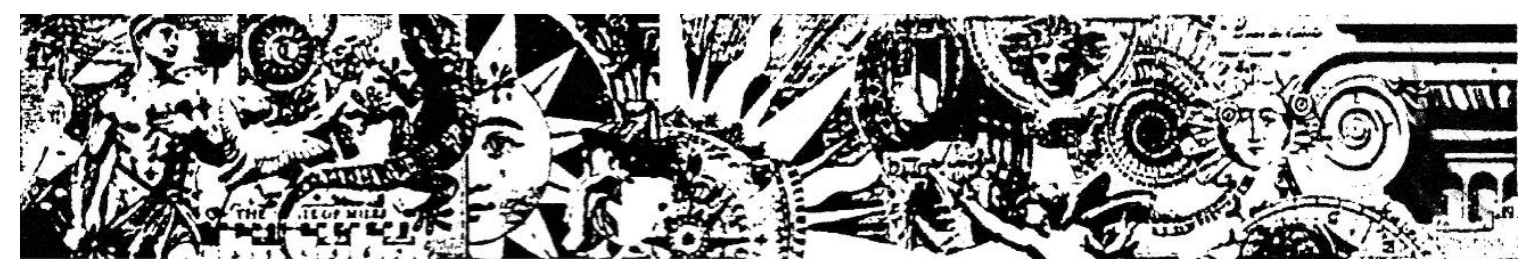

Resumo: Os midia, as novas tecnologias e as redes sociais, encontram-se no epicentro da comunicação que tanto pode promover valores religiosos de partilha, cooperação e afetividade civilizacional, como podem ser instrumentalizados por leituras mais radicalizadas que apelam a atitudes identitárias extremistas. Este é o domínio dos grupos terroristas que assentam a sua ideologia em leituras enviesadas dos textos sagrados e promovem mensagens de violência e ódio. A resposta a esta radicalização deve passar também pela comunicação e por uma diplomacia cultural que promova a paz.

Palavras-chave: Comunicação; radicalismos religiosos; terrorismo 


\section{GEOGRAPHY OF POWER, TRANSNATIONAL ACTORS AND COMMUNICATION IN RELIGIOUS RADICALIZATION PROCESSES}

Abstract: Media, new technologies and social networks are at the epicenter of communication that can both promote religious values of sharing, cooperation, and civilizational affectivity, as can be instrumented by more radical readings that appeal to extremist identity attitudes. This is the domain of terrorist groups who base their ideology on skewed readings of sacred texts and promote messages of violence and hate. The response to this radicalization must also include communication and a cultural diplomacy that promotes peace.

Keywords: Communication, religious radicalism, terrorism

\section{GEOGRAFÍA DEL PODER, ACTORES TRANSNACIONALES Y COMUNICACIÓN EN PROCESOS DE RADICALIZACIÓN RELIGIOSOS}

Resumen: Los media, las nuevas tecnologías y las redes sociales, se encuentran en el epicentro de la comunicación que tanto puede promover valores religiosos de compartición, cooperación y afectividad civilizadora, como pueden ser instrumentalizados por lecturas más radicalizadas que apelan a actitudes de identificación extremista. Este es el dominio de los grupos terroristas que asientan su ideología en lecturas sesgadas de los textos sagrados y promueven mensajes de violencia y odio. La respuesta a esta radicalización debe pasar también por la comunicación y por una diplomacia cultural que promueva la paz.

Palabras clave: Comunicación, radicalismo religioso, terrorismo

\section{Introdução}

Para Yuval Noah Harari (2018), para além dos factos concretos, nas dinâmicas sociais são importantes as crenças, as ficções e os mitos. O comportamento individual e coletivo depende, em parte, das perceções que se têm da realidade. Por sua vez, estas mesmas perceções são condicionadas por mensagens e narrativas que se constroem e divulgam a partir de um ou mais pontos de difusão. É nesta perspetiva, em muito centrada no poder da comunicação, que a religião e, em concreto, as interpretações dos textos religiosos, se impõem na política e em decisões de diferente natureza, entre as quais as de âmbito geográfico.

Apenas um exemplo. As leituras revivalistas e radicais de textos religiosos e a utilização de meios para a difusão destas mensagens desempenharam um papel relevante na revolução iraniana de 1979. A dispersão geográfica dos discursos do Ayatollah Khomeini por meio das celebrizadas casetes, foi um fator de radicalização religiosa e de intervenção política revolucionária, tendo em vista a islamização do país e o corte que, na época, o Irão promoveu 
face aos valores ocidentais. A partir de Paris, onde se exilou depois da saída do seu país em 1978, este líder religioso fez circular mensagens pelo território iraniano apelando a atitudes de desobediência civil, insurreição, boicotes e não cooperação (SCHOCK, 2005).

A relação entre meios de comunicação, religião e política, evidentes no caso da revolução iraniana, que alterou o quadro geopolítico no Próximo e Médio Oriente, é fundamental para se entenderem algumas das dinâmicas de um mundo contemporâneo instável, difuso e imprevisível.

Parte dessa instabilidade deve-se a uma geografia do poder complexa, líquida e difícil de cartografar (NAIM, 2014). 0 mapa dos Estados-nação, definido por áreas contínuas e fronteiras traçadas por linhas bem demarcadas, está agora confrontado por atores com espacialidades mais complexas. Tratam-se de protagonistas multiterritoriais que apresentam estratégias flexíveis de afirmação, controlo e sustentação de diferentes formas de poder (HAESBAERT, 2002 e 2004). 0 Estado, que regulava o sistema por métodos de controlo ajustados a fronteiras bem definidas, viuse confrontado com outros atores que se afirmam por lógicas territoriais mais flexiveis e difusas, contestando os princípios dominantes e reclamando uma nova ordem (HAESBAERT, 2007).

A criminalidade organizada em rede e os grupos terroristas, também estruturados por multiterritorialidades complexas (HAESBAERT, 2004), inserem-se neste conjunto de agentes que contestam a ordem estatal, aumentam a insegurança e a imprevisibilidade e contribuem para uma geografia do poder mais difusa, instável e difícil de cartograr com exatidão. Esta instabilidade, como se discutirá mais à frente, não está desligada da temática dos media e da comunicação e do modo como se agregam seguidores em torno de mensagens identitárias que, ao mesmo tempo que se consolidam num grupo de pertença, também se segregam face ao exterior desse confinamento.

Se é certo que as vagas mais recentes de terrorismo se têm organizado e estruturado numa era de comunicações digitais, também é verdade que esses movimentos de contestação agressiva e violenta viveram outros contextos nos quais a interligação entre os vértices e os atores dessas redes se realizavam utilizando canais de comunicação e instrumentos diferentes. 0 que daqui se ressalva é a forma como esses grupos hostis à ordem instalada, por um lado, se reuniam em torno de mensagens de unificação (nem sempre religiosas) e, por outro, dependiam de sistemas mais ou menos sofisticados de troca de mensagens de doutrinação e organização de operações de violência.

David Rapoport (2002) identifica quatro fases distintas na dinâmica das atividades terroristas. A primeira decorre entre 1880 e 1920 com as ações anarquistas iniciadas na Rússia, mas com alcance geográfico extensível a toda a Europa Ocidental e América do Norte. A segunda 
fase, anticolonialista, acontece nas primeiras décadas do século XX e está focada nos conflitos pela autodeterminação dos territórios e das populações dominadas por poderes coloniais externos. A terceira fase coincide com a vaga da nova esquerda, durante as décadas de 60 e 70. Está centrada na Europa Ocidental e terá tido origem na contestação da Guerra do Vietname.

Ainda para Rapoport (2002), é na quarta fase que a religião emerge enquanto fator de agregação, motivação e mobilização do grupo. Esta vaga religiosa, centrada no Islão, teve dois momentos importantes: a revolução iraniana de 1979 e o ataque ao World Trade Center, em Nova lorque, em 2001. Alguns autores, como Kaplan (2016), sugerem uma nova vaga terrorista, mais recente, de contornos ainda indefinidos, mas que aponta para o regresso dos tribalismos e para a deriva das identidades. Ainda assim, é certo que a religião vai assumindo um papel determinante no modo como estes atores transnacionais difusos, os grupos terroristas, se vão organizando e atuando. Esta agregação identitária em torno da religião ganhou um novo balanço com o processo de radicalização da Al Qaeda, desde o final do anos (1980) e, mais recentemente, com a génese do ISIS, o Estado Islâmico, que ocupou partes do território do Iraque e da Síria.

Ainda que as atuais vagas de terrorismo se sustentem em interpretações religiosas radicais, também nas anteriores fases de violência referidas por Rapoport (2002) se fizeram apelos a fatores identitários de união do grupo em torno de causas comuns. Entre esses valores e crenças, os dircursos religiosos foram condicionantes em conflitos territoriais como as sucessivas crises que, desde a criação de Israel (em 1948) e as disputas para a constituição de um Estado palestiniano, ocorreram no Próximo e Médio Oriente. O mesmo ocorreu noutras circunstâncias, como a divisão da ilha de Chipre entre cipriotas gregos ortodoxos e turcos islâmicos (em 1974). 0 mesmo se pode afirmar a respeito da disputa pela independência e unificação da totalidade da ilha irlandesa, acompanhada pelas ações violentas do Irish Republican Army (IRA) que, neste caso, traçou uma fronteira entre protestantes e católicos, ainda hoje visível em cidades como Belfast.

Ainda assim, para Rapoport (2002), a mais recente recuperação dos discursos políticos em torno da religião tem outro alcance. Enquanto sistema de valores, estes não se limitam a estruturar grupos que pretendam a criação de Estados laicos, mas definem princípios que justificam a instauração de uma ordem diferente, como se vislumbrou com a territorialidade pretendida pelo ISIS. Este novo mundo desejado, seria composto por Estados, ou outras entidades políticas, orientadas por leis religiosas escritas à luz das leituras extremistas de líderes radicais.

Ao longo do tempo, outras crenças religiosas foram também associadas a atos de terrorismo, como o cristianismo, a comunidade judaica, os sikhs ou o movimento Aum Shinrikyo 
que, em 1995, usou um gás tóxico para executar um ataque terrorista no metropolitano de Tóquio. Ainda que as suas motivações sejam difíceis de determinar, este grupo japonês filia-se numa complexa junção entre princípios budistas, cristãos e hindus. Ainda assim, prossegue o mesmo autor (RAPOPORT, 2002), nesta nova vaga é o islamismo que está no centro do foco, colocando as interpretações religiosas no centro da geografia difusa do poder. Enquanto ideologia com efeitos políticos, a difusão do islamismo terá, em diferentes momentos e circunstâncias, vários territórios de partida, do Iraque à Arábia Saudita, do Líbano ao Irão, ao Egipto ou ao Afeganistão.

As dinâmicas do terrorismo de inspiração islâmica estão alicerçadas em estratégias de radicalização religiosa, "processes by which individuals and/or groups come to adopt extremist ideologies" (HUSSAIM; SALTMAN, 2014, p. 10), um instrumento de poder ao qual recorrem os já citados Al Qaeda e ISIS. No entanto, nos movimentos radicais do passado, os contextos eram outros e as motivações ideológicas também não eram as mesmas. Nas últimas décadas, ocorreram também mudanças nas formas e nos instrumentos de comunicação. Por isso, 0 recrutamento dos fiéis, e dos exércitos de mobilização, apresenta hoje uma geografia diferente.

Como refere Rapoport (2002), se nalgumas organizações terroristas do passado recente, como o IRA ou a ETA, o recrutamento ocorria sobretudo numa base territorial restrita, a Irlanda ou o País Basco, no caso destas organizações islâmicas a radicalização passa por uma rede mais vasta de espaços geográficos, quase sempre distantes entre si.

Essa distância, considerada numa métrica euclidiana, é atenuada por estruturas eficazes de comunicação, como as diásporas, mas também pelas novas tecnologias de informação. Nesta perspetiva, as distâncias reais e efetivas encurtam-se e é mais fácil e constante a troca de ideias, mensagens e leituras mais extremistas e personalizadas dos textos sagrados. Das casetes de Khomeini às atuais potencialidades da internet, há um mundo de diferenças, aquelas que vão dos suportes analógicos de comunicação aos territórios do digital e do ciberespaço (Fernandes, 2014). Apesar de tudo, como se discutirá mais adiante, neste jogo político e ideológico, estes dois universos de comunicação não se opõem. Pelo contrário, complementam-se.

\section{Radicalização religiosa, identidades unidimensionais e potencial de violência}

Na perspetiva da radicalização, a comunicação é um instrumento que promove e difunde uma identidade monolítica baseada num único traço de unidade - a crença religiosa. Trata-se de um processo de simplificação identitária que reduz as vivências de múltiplas pertenças e as filiações compostas e complexas. Em alternativa, impõem-se narrativas de pertença única que, no 


\section{4:}

geral, se apoiam no acantonamento e na afirmação de um grupo sobre os outros (SEN, 2007; MAALOUF, 1999).

Nestas leituras do mundo, as distâncias culturais são manipuladas e artificialmente dilatadas. A radicalização religiosa de cariz islâmico, promovida com o recurso a diferentes canais de comunicação, é acompanhada pela inculcação do medo e pela demonização do ocidente, em especial dos Estados Unidos da América, com frequência apresentados como o inimigo supremo que se deve combater, no interior mas também no exterior do mundo árabe. Este maniqueísmo, não sendo exclusivo da radicalização islâmica, acaba por alimentar teorias conspirativas e fragmentar mundividências que, no limite, apontam para as teses do choque das civilizações assinaladas nos trabalhos de Samuel L. Huntington (1999).

Para Francis Fuluyama (2018), esta comunicação que radicaliza encontra um campo fértil nas sociedades árabes e islâmicas que, ao longo da segunda metade do século $X X$, ou se urbanizaram em cidades como o Cairo, Damasco ou Bagdad, ou se foram deslocando através de correntes migratórias para os vértices das diásporas, em metrópoles como Londres, Roterdão, Bruxelas ou Paris. Para Fukuyama (2018), socorrendo-se da obra do sociólogo alemão do século XIX, Ferdinand Tönnies, a transformação da Gemeinschaft (uma sociedade rural mais coesa) numa Gesellschaft (uma sociedade urbana mais fluída, plástica e líquida), contribuiu em muito para a deriva identitária destas populações.

Neste campo fértil para a receção de discursos religiosos com propósitos políticos, a unidade perdida recupera-se pela pertença a uma comunidade transnacional (a umma) que, ao mesmo tempo que invoca valores tradicionais e vernaculares interpretados à medida dos interesses das lideranças, acaba por tirar partido das novas plataformas e instrumentos de comunicação.

Contudo, os mesmos conceitos podem implicar universos diferentes. Para Zygmunt Bauman (2003, p.7), "As palavras têm significado: algumas delas, porém, guardam sensações. A palavra 'comunidade' é uma dessas. Ela sugere uma coisa boa: o que quer que 'comunidade' signifique, é bom 'ter uma comunidade' 'estar numa comunidade'. Se alguém se afasta do caminho certo, frequentemente explicamos sua conduta reprovável dizendo que 'anda em má companhia'. Se alguém se sente miserável, sofre muito e se vê persistentemente privado de uma vida digna, logo acusamos a sociedade - o modo como está organizada e como funciona. As companhias ou a sociedade podem ser más; mas não a comunidade. Comunidade, sentimos, é sempre uma coisa boa." 
Ainda assim, as comunidades que agora se reorganizam, associando as velhas métricas geográficas euclidianas de proximidade com as novas geografias dos fluxos e das redes topológicas transnacionais, aquelas que se sustentam em políticas de identidade, podem assumir uma estratégia perversa e violenta, quando se orientam por lógicas de exclusão e se organizam em arquiteturas espaciais e mentais de enclave e confinamento.

Meios de comunicação como o cinema e a televisão, mas também agora todas as plataformas digitais que se cruzam com esses veículos de informação, não estão isentos de responsabilidades na criação deste campo fértil de radicalização religiosa. $\mathrm{Na}$ pop culture dominante, faz-se a representação simplista da humanidade, opondo as imagens de territórios ricos e felizes, associados a uma vaga noção de ocidente, à transmissão de paisagens de pobreza, instabilidade e insegurança, na outra metade do mundo. Assim se têm alimentado visões unidimensionais e estereotipadas da realidade (AVRAHAM; KETTER, 2008).

Nada será assim tão simples e direto. No entanto, saber da existência de um outro mundo pode levar à resignação, poderá gerar o desejo de partir, mas pode também alimentar a resposta mais radical e violenta. É mais fácil a difusão do extremismo nas populações que, em cidades como Kabul, Islamabad ou Bagdad, ou nos territórios rurais mais longínquos destes espaços urbanos, percecionam a distância e sentem goradas as suas expetativas. 0 mesmo ocorre, sobretudo na população jovem que, em bairros como Molenbeek, em Bruxelas, sente a distância e um fosso social relativamente às sociedades urbanas ocidentais do seu entorno.

Ainda que a radicalização passe também por indivíduos na aparência bem integrados e envolvidos em instituições como universidades, este aparente falhanço da multiculturalidade em muitos países europeus não pode deixar de ser uma base de reflexão em matérias que interferem no futuro do próprio projeto europeu. Este estará mal adaptado a realidades que desconhece e a novos padrões da sua Geografia Cultural que não controla (SHORE, 2007; MURRAY, 2018).

\section{A comunicação nos processos de radicalização religiosa- algumas notas de reflexão}

Ainda que a religião possa ser entendida como um universo interior e uma vivência espiritual, a mensagem religiosa passa sempre por qualquer modo de comunicação. As paisagens sonoras das cidades islâmicas estão marcadas pelos ritmos disciplinadores e pelas vozes reguladoras dos muezim, que comunicam com os fiéis por meio de altifalantes instalados no alto dos minaretes das mesquitas. 0 mesmo acontece, e o catolicismo é disso exemplo, com as sonoridades de outros rituais que exorcisam crenças e promovem a unidade de grupo. A 
verticalidade da comunicação nas missas dominicais, mas também a sonoridade dos sinos instalados nas torres das igrejas, fazem parte dessa soundscape que comunica acontecimentos, agrega os grupos e une fiéis (AUGUSTO, 2014).

No entanto, também a radicalização se promove pelo ato de criar e difundir mensagens. A relação direta entre o emissor e os recetores não abandonou os meios e os ambientes analógicos. Assim ocorre no islão e noutras crenças religiosas. No caso do radicalismo islâmico, em muitos casos, as mesquitas e as madrassas (ou escolas corânicas) podem ser lugares de difusão de ideias mais extremistas. Para Thomas L. Friedman (2015), o wahabismo radical saudita estará mesmo a revelar-se a partir de uma rede de mesquitas que, de Marrocos ao Paquistão e à Indonésia, ali têm promovido correntes ativas de jihadismo.

A geografia pouco visível, muitas vezes subterrânea, dessa difusão, passa por espaços como alguns estabelecimentos prisionais ou campos de refugiados, universidades, associações cívicas, grupos de estudantes, livrarias ou cafés, ou ainda pelos contactos pessoais nos interstícios mais discretos de bairros urbanos europeus, como Molenbeek, em Bruxelas. Com efeito, seguindo Rogério Haesbaert (2002), esta radicalização tira partido de aglomerados de exclusão, como os bairros mais carenciados de certas áreas urbanas. Esta será uma rede de microterritórios e de incubadoras de grupos terroristas, a partir dos quais se promovem ideias e crenças e se estimulam operações com impacto mediático elevado (DEVROE; PONSAERS, 2018; SILBER; BHATT, 2007).

Contudo, grande parte dessa filiação a teses religiosas e ideológicas extremistas passa pela comunicação à distância, pelas novas tecnologias de informação e comunicação e pelas espacialidades topológicas que tanto têm afetado as geografias do poder. Esta estratégia, que promove leituras e narrativas revivalistas e fundamentalistas da religião, tira partido de um mundo digital, da internet e das redes sociais, no qual é fácil, rápido e incontrolável a difusão de informações filtradas por ideologias radicais mas pouco reguladas pelos poderes políticos convencionais.

Como se referiu, comunica-se de modo direto nas mesquitas, nas madrassas e nos bairros mais pobres de algumas cidades europeias, mas também à distância e de forma indireta através do Facebook, do Youtube ou do WhatsApp.

Esta diversidade de canais é testemunha do balanço que Niall Ferguson (2017) assinala entre, por um lado, a comunicação promovida no contexto de instituições tradicionais, verticalizadas e hierarquizadas (as escolas corânicas e as mesquitas, por exemplo) e, por outro, a comunicação difundida segundo lógicas horizontais organizadas em redes. Ao primeiro caso, 
Ferguson (2017) faz uma associação metafórica com as torres - a verticalidade que vigia o entorno e, ao segundo, com as praças, o espaço mais aberto e indefinido no qual circulam mensagens e informações de origem e trajetórias indefinidas.

Entre estes estes dois elementos, as metafóricas torres e praças, nem sempre a fronteira é nítida. De resto, como refere Ferguson (2017), nas estratégias de luta pelo poder, as plataformas analógicas e digitais, assim como os contactos de proximidade e à distância, complementam-se mutuamente. Como se viu no exemplo de Khomeini ainda no século XX, as velhas hierarquias religiosas promovem-se pelo contacto direto efetuado a várias escalas geográficas mas não descuram a utilização de tecnologias de comunicação à distância.

Nestas, em contexto de grupos como a AI Qaeda e o ISIS, foi frequente a utilização de mensagens visuais, em particular filmes divulgados por plataformas como 0 Youtube, nas quais se mostraram atos violentos de intimidação, recrutamento e incitação ao ódio. Discutindo o papel da comunicação e da difusão no contexto da Geografia Cultural, Paul Claval (2006) indica que as mensagens visuais incorrem em menores riscos de perda de informação entre 0 emissor e 0 recetor. Seguindo este ponto de vista, compreende-se que o recurso à imagem seja condição para uma comunicação mais direta, eficaz e, porventura, menos questionável.

No entanto, tal como nas velhas geografias analógicas, também no ciberespaço se podem utilizar os meandros mais obscuros e subterrâneos de comunicação e divulgação. É na denominada Dark Net, os espaços digitais escondidos que escapam aos motores de busca usuais, como o Google, que circula parte importante destas mensagens radicais de extremismo religioso, recrutamento e organização de operações violentas (WEIMANN, 2018).

No entanto, os processos de radicalização religiosa e promoção do poder de organizações fundamentalistas radicais passam por outros caminhos. Por exemplo, pela criação de canais de difusão próprios e de agências noticiosas controladas. Assim ocorreu com a Agência de Notícias Amaq, com ligação privilegiada ao ISIS. Recorrendo a aplicações encriptadas de telemóveis, era para esta agência que o grupo terrorista enviava mensagens diretas e em tempo real. As operações violentas do grupo chegaram a ser acompanhadas por jornalistas desta mesma organização. Esta Amaq era também a primeira agência a anunciar a autoria do ISIS em diferentes ataques terroristas (CALLIMACHI, 2016).

Ainda segundo Rukmini Callimachi (2016), depurando e atenuando as referências mais ideológicas e violentas, comuns nas mensagens diretas divulgadas por este grupo extremista, esta agência noticiosa recorria a palavras mais suaves e neutras. Por exemplo, utilizava o conceito de 
"combatentes do Estado Islâmico", em vez dos "soldados do Califado" preferidos pelo Estado Islâmico. Para a Amaq, as vítimas seriam "cidadãos estrangeiros" e não "cruzados".

Isso não obsta a que, e seguimos ainda Callimachi (2016), esta falsa agência noticiosa tenha sido um braço de propaganda desse grupo islâmico radical. 0 objetivo seria, ao mesmo tempo, dar visibilidade e credibilidade ao ISIS. Por outro lado, o Estado Islâmico manteve a sua estação oficial de rádio (a Al Bayan), com a transmissão diária de mensagens, assim como a Dabiq, uma revista mensal. Também a divulgação de vídeos era promovida por empresas de media que prepararam, organizaram e difundiram essas gravações com o intuito de criar medo, intimidar e atrair seguidores. Tal como refere Callimachi (2016), o ISIS comportou-se como um Estado que pretendia controlar a sua máquina oficial de notícias e propaganda. $O$ uso do pretérito nesta fase do texto não é casual. Com efeito, uma sucessão de reveses no terreno tem conduzido esta estratégia à derrota. Por exemplo, em março de 2018, o The Meir Amit Intelligence and Terrorism Information Center (2018), dava conta que, no decorrer de ações militares na cidade de Mosul, haviam sido capturados jornalistas que estavam ao serviço do ISIS e um editor do semanário Al-Nabā', para além de outros operacionais ao serviço da agência Amaq.

\section{Notas Finais}

A comunicação, em espaço analógico ou nos inovadores territórios digitais, constitui um instrumento de poder, porventura um meio de soft power, como refere Joseph Nye (2014) mas, ainda assim, um fator determinante no domínio da religião e da intervenção política.

As novas tecnologias de informação e as redes sociais, por exemplo, podem constituir um meio de afirmação benigna dos valores religiosos e de manutenção dos laços de filiação em comunidades agora afetadas por fatores centrífugos como as mobilidades espaciais, o ritmo e a velocidade do quotidiano. Nesta perspetiva mais otimista, as novas tecnologias de informação poderão estar ao serviço do estabelecimento de pontes civilizacionais e da promoção de valores universais de partilha.

O poder é hoje difuso, mas a comunicação e a religião estão no centro desse poder. Contudo, a comunicação livre é um instrumento de exercício da cidadania em sociedades abertas, mas a desregulação das plataformas incorre em riscos. Os avanços no mundo digital promoveram a plasticidade difusa deste universo, difícil de controlar, sobretudo no contexto das democracias liberais, embora aconteça o mesmo noutros regimes mais fechados. 
Essas mesmas tecnologias de comunicação, pelo seu caráter disruptivo, pela democratização dos acessos e pela flexibilidade de expansão, podem ser instrumentos de propagação de narrativas fundamentalistas que se projetam em processos de radicalização e recrutamento. Isso serve para o campo religioso mas também para o caso dos extremismos políticos.

Neste domínio da comunicação, do mundo digital, dos novos media, da religião e da política, todas os ângulos são possíveis. As novas tecnologias, ao mesmo tempo que promovem mensagens radicais, podem ser também um espaço de resistência e contestação. É neste campo que se desafiam as ideologias religiosas radicais que condicionam os quotidianos e os estilos de vida. Assim tem ocorrido, apenas um exemplo, com manifestações públicas de mulheres iranianas que, utilizando câmaras de smartphones, gravam e divulgam vídeos prevaricando de forma deliberada algumas das restrições impostas pelos fundamentalistas islâmicos à população do sexo feminino, como o direito a dançar.

Com efeito, os media, as tecnologias de informação, as plataformas e as redes sociais, constituem uma agregação confusa que se sintetiza na ideia de comunicação, que tanto pode ser instrumentalizada para mensagens radicais, como pode também intermediar e dar visibilidade a atos de resistência e contestação a essa radicalização.

Por último, é importante referir que a comunicação é também fundamental nos processos de desradicalização, que devem beneficiar de uma abordagem multidisciplinar. Como se pode verificar, no caso português, através do "Plano de Ação para a Prevenção da Radicalização, dos Extremismos violentos e do Recrutamento para o Terrorismo", aprovado no âmbito da Estratégia Nacional de Combate ao Terrorismo, a resposta ao fundamentalismo passa pela criação de narrativas de comunicação que contrariem as leituras mais radicais. Para ganharem maior poder de disuasão, esta contra informação positiva e construtiva deve passar por focos de difusão no interior do próprio Islão. As madrassas e as mesquitas que estão fora dessa rede de radicalismo, devem ter papel importante na transmissão de valores ecuménicos de cooperação, proximidade e promoção da paz.

Como refere Adélio Neiva Cruz, diretor do Serviço de Informações de Segurança (SIS), de Portugal, a propósito do regresso à Europa de antigos combatentes do ISIS (citado por Pinto, 2018, p.55), "a prevenção começa na definição de políticas públicas que favoreçam a integração das comunidades, que desenvolvam os processos de acolhimento, que estimulem o sentimento de pertença à comunidade e aos valores democráticos, que criem uma narrativa alternativa à 
ideologia islamista jihadista e estruturem uma abordagem integrada, multidisciplinar, flexível, dinâmica e de natureza transversal".

Com efeito, ao discurso da radicalização, deve opor-se o da diplomacia cultural, um dos temas centrais nas próximas décadas deste século XXI. Também a comunicação, os media, as novas tecnologias, as plataformas digitais ou as redes sociais, assumem aqui uma posição relevante, sobretudo no vetor nuclear dessa diplomacia cultural: a religião, os discursos religiosos e as identidades.

\section{Referências}

AUGUSTO, Carlos Alberto. Sons e silêncios da paisagem sonora portuguesa; Ensaios da Fundação; Fundação Francisco Manuel dos Santos; Lisboa, 2014.

DEVROE, Elke; PONSAERS, Paul. "Terrorism and Governance Strategies in Brussels", in Forensic Research \& Criminology International Journal, 6(1), pp.20-26, 2018

AVRAHAM, Eli; KETTER, Eran. Media strategies for marketing places in crisis; ButterworthHeinemann; Elsevier; Amsterdam, 2008.

BAUMAN, Zygmunt. Comunidade: A busca por segurança no mundo atual; Jorge Zahar Editor; Rio de Janeiro, 2003.

CALLIMACHI, Rukmini. A News Agency with Scoops Directly From ISIS; in New York Times, edição de 15 de junho, pp. 10, 2016.

CLAVAL, Paul. "Comunicação, diferenciação de culturas e organização do espaço (noçõeschave)"; in João Sarmento et al (coord.), Ensaios de Geografia Cultural; Livraria Editora Figueirinhas; Porto, 2006.

FERGUSON, Niall. The square and the tower. Networks, hierarchies and struggle for global power; Penguin Books; London, 2017.

FERNANDES, José Pedro Teixeira. Ciberguerra; Guerra \& Paz; Quidnovi; Lisboa, 2014.

FRIEDMAN, Thomas L. "Our Radical Islamic BFF, Saudi Arabia", in New York Times; 2nd september, pp. 25, 2015.

FUKUYAMA, Francis. Identidades: a exigência de dignidade e a política do ressentimento; Publicações Dom Quixote; Lisboa, 2018.

HAESBAERT, Rogério. "A multiterritorialidade do mundo e o exemplo da AI Qaeda"; in Terra Livre, vol I, n.18; São Paulo, Brasil, 2002.

HAESBAERT, Rogério. O mito da desterritorialização; Bertrand Brasil; Rio de Janeiro. 2004. 
HAESBAERT, Rogério. "Sociedade de in-segurança e des-controle dos territórios"; Anais do I Encontro Nacional da ABRI - Associação Brasileira de Relações Internacionais; Brasília, 2007.

HARARI, Yuval Noah. 21 lições para o século XXI; Elsinore; Coimbra, 2018.

HUNTINGTON, Samuel P. O Choque das Civilizações e a Mudança na Ordem Mundial; Gradiva; Lisboa, 1999.

HUSSAIN, Ghaffar; SALTMAN Erin Marie. Jihad Trending: A Comprehensive Analysis of Online Extremism and How to Counter it; Quilliam Foundation, 2014.

KAPLAN, Jeffrey. Radical Religion and Violence Theory and case studies; Routledge; London, 2016.

MAALOUF, Amin. Identidades Assassinas; Col. Literatura estrangeira; Difel; Lisboa. 1999.

MURRAY, Douglas. A estranha morte da Europa. Imigração, identidade, religião; Edições Desassossego; Porto Salvo, 2018.

NAIM, Moisés. The end of power: From boardrooms to battlefields and churches to States, why being In charge isn't what it used to be; Basic Books; New York, 2014.

NYE, Joseph S. O futuro do poder; Temas e Debates; Círculo de Leitores; Lisboa, 2014.

PINTO, Nuno Tiago. "Quem são as mulheres e os filhos da Jihad", in revista Sábado, $n^{0} 756$, de 25 a 31 de outubro, pp. 50-55, 2018.

RAPOPORT, David C. "The Four Waves of Rebel Terror and September 11", Anthropoetics VIII, no. 1 Spring/ Summer_in http://anthropoetics.ucla.edu/ap0801/terror/\#b1, 2002.

SCHOCK, Kurt. Unarmed insurrections; University of Minnesota Press, 2005.

SEN, Amartya. Identidade e violência; Tinta da China; Lisboa, 2007.

SHORE, Zachary. Criando Bin Ladens. A América, o islão e o futuro da Europa; Bizâncio; Lisboa, 2007.

SILBER, Mitchell e BHATT, Arvin. 'FBI Counterterrorism Division. The Radicalization Process: From Conversion to Jihad'. Federal Bureau of Investigation, Washington D.C, 2006. Disponivel em: http://cryptome.org/fbijihad.pdf (acedido em 16 Fevereiro 2018 )

THE MEIR AMIT INTELLIGENCE AND TERRORISM INFORMATION CENTER. Spotlight on global jihad, 22-28 march; Israeli Intelligence Heritage and Commemoration Center; Ramat Hasharon; Israel, 2018

WEIMANN, Gabriel. Going Darker? THE CHALLENGE OF DARK NET TERRORISM; Wilson Center; Washington, DC, 2018. 